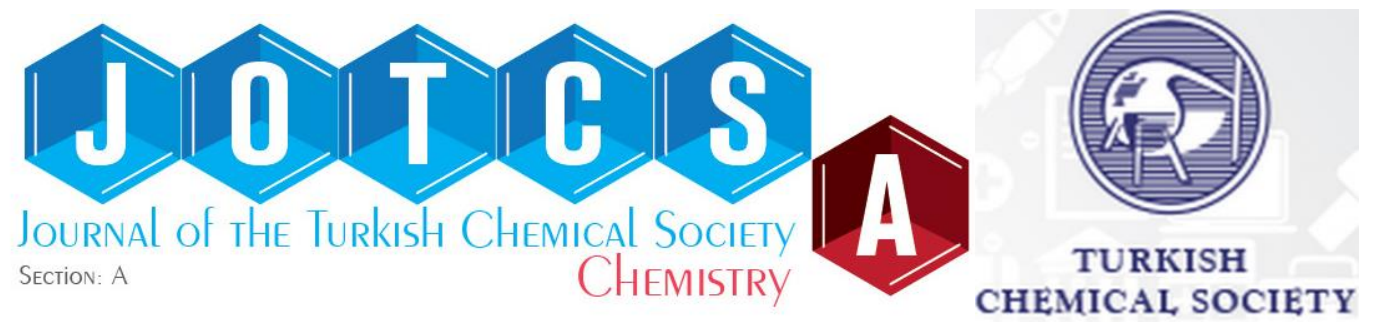

\title{
Synthesis of (Thio)substituted -1,3-Butadienes and -Butenynes
}

\author{
Aysecik Kacmaz ${ }^{1 *}$ (D) \\ ${ }^{1}$ Istanbul University - Cerrahpasa, Engineering Faculty, Chemistry Department, 34320, Avcilar, Istanbul, \\ Turkey
}

Abstract: In this study, 2H-1,1,3,4,4-pentachloro-1,3-butadiene (1) was reacted with different thiols (2methyl-2-propanethiol 2a, benzyl mercaptan $\mathbf{2 b}$, 4-tert-butylbenzenethiol 2c, 4-nitrothiophenol $\mathbf{2 d}$ ) in ethanol in the presence of $\mathrm{NaOH}$ to afford mono-thio-substituted-1,3-butadienes and mono- and tris-thiosubstituted-1-buten-3-ynes. Among them, (4-tert-butylphenyl)(1,3,4,4-tetrachlorobuta-1,3dienyl)sulfane (4c) exhibited two isomers of mono products. Moreover, the reaction of compound (1) with 2-hydroxythiophenol (2e) in dimethylformamide in the presence of triethylamine took place the formation of $\mathrm{OH}$-protected butadiene structure 2-((Z)-1,3,4,4-tetrachlorobuta-1,3-dienylthio)phenol (4e) and ringclosed butadiene structure (E)-2-(2,3,3-trichloroallylidene)benzo[d][1,3]oxathiole $(6)$, together and with two isomers of each. Their structures identified on the basis of GC-MS(+EI) analysis with different retention times (RT). Characterization of the synthesized compounds was done using several methods, mass spectrometry (GC-MS(+EI)), ${ }^{1} \mathrm{H}-,{ }^{13} \mathrm{C}-$, APT- NMR, FTIR and elemental analysis.

Keywords: Thioethers, 1-buten-3-ynes, 1,3-butadienes, GC-MS, thiols.

Submitted: March 07, 2019. Accepted: April 11, 2019.

Cite this: Kacmaz A. Synthesis of (Thio)substituted -1,3-Butadienes and -Butenynes. JOTCSA. 2019;6(2):201-6.

DOI: https://dx.doi.org/10.18596/jotcsa.536853.

*Corresponding author. E-mail: kacmaz@istanbul.edu.tr

\section{INTRODUCTION}

Organosulfur compounds are widely found in natural products (1) and play a major role in many biological systems (2). In this field of organosulfur chemistry, thioether moieties are essential fragments of many biologically active compounds $(3,4)$. For example, a-fluorinated thioethers are valuable compounds for modern agrochemicals (5). Also, there is a US patent (6) that discloses some thio derivatives of haloalkylpolyenes and their biological, specifically fungicidal, activities. Additionally, compounds with high sulfur content constitute an important class of materials chemistry, supramolecular chemistry, and polymer chemistry (7). In this respect, synthesis of a lot of organosulfur compounds are going on.

Also, polyhalo-1,3-butadienes and conjugated en-ynes are valuable precursor for various synthetic applications $(8,9)$. In addition, sulfonylsubstituted-1,3-butadienes and allenyl sulfones are used as the starting materials some reactions (Diels-Alder, Michael additions, etc.) (9-11).

Reactions of polyhalo-dienes and -butenes with thiols or amines have been previously reported by Ibis and co-workers and Roedig and coworkers (12-26). Yoshimatsu et al. reported the preparation of 2-sulfonyl-1-buten-3-ynes and their reactions with nucleophiles (9).

It is reported by our laboratory, that the reaction between $\mathbf{1}$ and different thiols under mild conditions results the formation of thiosubstituted 1,3-butadienes/butenynes (12-14). Among them, in 2010 (19) and 2016 (20), we reported that some mono-, bis-, tris- and tetrakis- substituted butenynes, butadienes or buta-1,2,3-trienes and their halogenation (iodination/bromination) and oxidation of some butadienes to their corresponding sulfoxides or sulfones. In these studies, in order to product mono-, bis- , tris- or tetrakis-substituted thioethers, having butadiene or butenyne skeleton, we used different reactant ratio and 
different reaction medium (DMF/triethylamine, $\mathrm{EtOH} / \mathrm{NaOH}$ etc.) via nucleophilic reactions.

Taking into account the above mentioned facts, it is reported herein the synthesis and structural characterization of some butenynes or 1,3butadienes, which having thioether skeleton.

\section{MATERIAL AND METHODS}

Infrared spectra (IR) were recorded on a Perkin Elmer Spectrum One FTIR instrument. GC-MS spectra, equipped with an Electron Impact (EI) source, were recorded on a Thermo Finnigan Trace DSQ system using $\mathrm{He}$ as carrier gas. ${ }^{1} \mathrm{H}$ $\mathrm{NMR},{ }^{13} \mathrm{C}$ NMR spectra in $\mathrm{CDCl}_{3}$ were recorded on a Varian Unity Inova spectrometer, with tetramethylsilane (TMS) as standard. Elemental analyses were performed on a Thermo FinniganFlash EA 1112 Series Elemental Analyzer. UV-vis spectra were taken from Perkin Elmer Lambda 35 UV-Vis spectrophotometer.

General Procedure for the Synthesis of Thioethers (3a, 3b, 3c, 3d, 4b, 4c, 4d and 5a) Synthesis of thioethers (3a, 3b, 3c, 3d, 4b, 4c, $\mathbf{4 d}$ and $\mathbf{5 a}$ ) were carried out by the reaction of $\mathbf{1}$ (8.8 mmol) with equimolar amount of different thiols (2-methyl-2-propanethiol 2a, benzyl mercaptan $\mathbf{2 b}$, 4-tert-butylbenzenethiol 2c, 4nitrothiophenol 2d) in ethanol $(20 \mathrm{~mL})$ with $\mathrm{NaOH}$. After the progress/completion of the reaction was monitored by thin layer chromatography (TLC), the resulting mixture was extracted with chloroform and water. The organic phase was dried by adding anhydrous $\mathrm{Na}_{2} \mathrm{SO}_{4}$ and evaporated under vacuum. The crude product was purified by column chromatography with nhexane over silica gel to yield products. The physical and spectral data of the products are as follows.

Synthesis of tert-butyl(3,4,4-trichlorobut-3en-1-ynyl)sulfane (3a) and 1,1,4-tris(tertbutylthio)-2-chlorobut-1-en-3-yne (5a)

Compounds $\mathbf{3 a}$ and $\mathbf{5 a}$ were synthesized according to general procedure:

3a: Known compound $(27,28)$ : Spectral data were in agreement with literature values. Yield (36\%), MS (El, $70 \mathrm{eV}) \mathrm{m} / \mathrm{z}(\%): 242.0\left(\mathrm{M}^{+}, 6\right)$, 244.0 (6), 186.0 (12), 188 (12), 114.9 (15), 57.0 (100), 41.0 (48), 29.1 (36); Anal.Calcd. for $\mathrm{C}_{8} \mathrm{H}_{9} \mathrm{Cl}_{3} \mathrm{~S}$ (243.58): C, 39.45; $\mathrm{H}, 3.72 ; \mathrm{S}, 13.16$. Found: $\mathrm{C}, 39.43 ; \mathrm{H}, 3.70 ; \mathrm{S}, 13.14$.

5a: Light yellow oil, Yield (5\%), $\mathrm{R}_{\mathrm{f}}$ (n-hexane): 0.3 ; IR spectrum, $\mathrm{v}, \mathrm{cm}^{-1}: 2134$ (C $\left.\equiv \mathrm{C}\right), 2962$, 2921, 2861, 1456, 1260, 799; ${ }^{1} \mathrm{H}$ NMR spectrum, $\delta$, ppm: $1.39\left(\mathrm{~s}, \mathrm{CH}_{3}\right), 1.42\left(\mathrm{~s}, \mathrm{CH}_{3}\right)$; APT NMR spectrum, $\delta \mathrm{C}$, ppm: 93.72, 89.92 (C $\equiv \mathrm{C}), 133.89$, $126.58(\mathrm{C}=\mathrm{C}), 50.00,49.09,48.16\left(\mathrm{C}-\mathrm{CH}_{3}\right)$, $30.47,30.45,30.30,30.27,30.24,29.80,29.77$, 29.61, $29.58\left(\mathrm{CH}_{3}\right)$; MS (El, $\left.70 \mathrm{eV}\right) \mathrm{m} / \mathrm{z}(\%)$ : $350.2\left(\mathrm{M}^{+}, 6\right), 352.2(2.5), 238.1$ (10), 240.1 (5), 182.0 (54), 57.1 (100), 146.0 (9); Anal.Calcd. for $\mathrm{C}_{16} \mathrm{H}_{27} \mathrm{ClS}_{3}$ (351.03): C, 54.74; H, 7.75; S, 27.40. Found: C, 54.72; H, 7.72; S, 27.42.
Synthesis of benzyl(3,4,4-trichlorobut-3-en1-ynyl)sulfane (3b) and benzyl $(1,3,4,4-$ tetrachlorobuta-1,3-dienyl)sulfane (4b)

Compounds $\mathbf{3 b}$ and $\mathbf{4 b}$ were synthesized according to general procedure:

3b: Yellow oil, Yield (40\%), $\mathrm{R}_{\mathrm{f}}$ (n-hexane): 0.5; IR spectrum, $\mathrm{v}, \mathrm{cm}^{-1}: 2151$ ( $\left.\mathrm{C} \equiv \mathrm{C}\right), 3063,3031$, $1459,1454,958 ;{ }^{1} \mathrm{H}$ NMR spectrum, $\delta, \mathrm{ppm}: 4.05$ (s, $\left.\mathrm{CH}_{2 \text { benzyl }}, 2 \mathrm{H}\right), 7.3-7.4\left(\mathrm{~m}, \mathrm{CH}_{\text {arom }}, 5 \mathrm{H}\right) ;{ }^{13} \mathrm{C}$ NMR spectrum, $\delta C, p p m: 138.08,129.33$, $129.27,128.99,128.89,128.36,113.08\left(\mathrm{CH}_{\text {arom, }}\right.$ $\left.\mathrm{C}=\mathrm{C}_{\text {buten }}\right), 87.88,92.47(\mathrm{C} \equiv \mathrm{C}), 40.83\left(\underline{\mathrm{CH}}_{2 \text { benzyl }}\right)$; MS (El, $70 \mathrm{ev}) \mathrm{m} / \mathrm{z}(\%): 278.1\left(\mathrm{M}^{+}, 31\right), 241.1$ (100), 206.1 (74), 115.0 (77); Anal. Calcd. for $\mathrm{C}_{11} \mathrm{H}_{7} \mathrm{Cl}_{3} \mathrm{~S}$ (277.6): C, 47.59; $\mathrm{H}, 2.54 ; \mathrm{S}, 11.55$. Found: $\mathrm{C}, 47.57 ; \mathrm{H}, 2.52 ; \mathrm{S}, 11.53$.

4b: Yellow oil, Yield (7\%), $\mathrm{R}_{\mathrm{f}}$ (n-hexane): 0.6; IR spectrum, v, cm${ }^{-1}$ : 3064, 3030, 2926, 2853, $1602,1567,1495,1454,942 ;{ }^{1} \mathrm{H}$ NMR spectrum, $\delta$, ppm: $4.18\left(\mathrm{~s}, \mathrm{CH}_{2 \text { benzyl }}, 2 \mathrm{H}\right), 6.48(\mathrm{~s}, 1 \mathrm{H}$, $>\mathrm{C}=\mathrm{CH}), 7.3-7.4\left(\mathrm{~m}, \mathrm{CH}_{\text {arom }}, 5 \mathrm{H}\right) ;{ }^{13} \mathrm{C}$ NMR spectrum, $\delta C$, ppm: 136.40, 129.22, 129.13, $128.92,127.90,126.98,126.29,126.27,124.51$, 122.19, 40.84; MS (El, 70 ev) $\mathrm{m} / \mathrm{z}(\%): 314.1$ $\left(\mathrm{M}^{+}, 15\right), 186.0(100)$; Anal.Calcd. for $\mathrm{C}_{11} \mathrm{H}_{8} \mathrm{Cl}_{4} \mathrm{~S}$ (314.06). C, 42.07; H, 2.57; S, 10.21. Found: C, $42.05 ; \mathrm{H}, 2.55 ; \mathrm{S}, 10.23$.

Synthesis of (4-tert-butylphenyl)(3,4,4trichlorobut-3-en-1-ynyl)sulfane (3c) and (4-tert-butylphenyl) $(1,3,4,4-$ tetrachlorobuta-1,3-dienyl)sulfane (4c, isomer mixture)

Compound $\mathbf{3 c}$ and $\mathbf{4 c}$ were synthesized according to general procedure:

3c: Known compound $(26,29)$. Spectral data were in agreement with literature values. $R_{f}(n-$ hexane): 0.9; APT NMR spectrum, $\delta C$, ppm: 89.96, 89.46 ( $\mathrm{C} \equiv \mathrm{C}), 113.07,126.59$ ( $\mathrm{C}=\mathrm{C})$, $151.21,127.41$ ( $\left.\mathrm{C}_{\text {arom }}\right), 127.24,126.92\left(\mathrm{CH}_{\text {arom }}\right)$, $31.44\left(3 \mathrm{CH}_{3}\right), 34.85\left(\mathrm{C}-\mathrm{CH}_{3}\right) ; \mathrm{MS}(\mathrm{El}, 70 \mathrm{ev}) \mathrm{m} / \mathrm{z}$ (\%): $320.2\left(\mathrm{M}^{+}, 45\right), 322.2(16), 303.1$ (100), 117.1 (42), 233.2 (11); Anal.Calcd. for $\mathrm{C}_{14} \mathrm{H}_{13} \mathrm{Cl}_{3} \mathrm{~S}$ (319.68). C, 52.60; H, 4.10; S, 10.03 . Found: C, 52.58; H, 4.12; S, 10.01 .

4c, isomer mixture: Light yellow oil, Yield (50\%), $\mathrm{R}_{\mathrm{f}}$ (n-hexane): 0.8; IR spectrum, $\mathrm{v}, \mathrm{cm}^{-1}$ : 2962, 2905, 2869, 1594, 1570, 1489, 1263, 823; ${ }^{1} \mathrm{H}$ NMR, $\delta, \mathrm{ppm}: 6.14(\mathrm{~s}, 1 \mathrm{H},>\mathrm{C}=\mathrm{CH}), 6.48$ (s, $1 \mathrm{H},>\mathrm{C}=\mathrm{CH}), 7.37(\mathrm{~s}, 4 \mathrm{H}, \mathrm{Ar}-\mathrm{H}), 7.32(\mathrm{~s}, 4 \mathrm{H}, \mathrm{Ar}-$ $\mathrm{H}), 1.26(\mathrm{~s}, 3 \mathrm{H}, \mathrm{Me}), 1.257(\mathrm{~s}, 3 \mathrm{H}, \mathrm{Me}), 1.253$ (s, $3 \mathrm{H}, \mathrm{Me}), 1.249$ ( $\mathrm{s}, 3 \mathrm{H}, \mathrm{Me}), 1.243(\mathrm{~s}, 3 \mathrm{H}, \mathrm{Me})$, $1.23(\mathrm{~s}, 3 \mathrm{H}, \mathrm{Me}) ;$ APT NMR, $\delta \mathrm{C}, \mathrm{ppm}: 152.24$, $151.46,137.61,137.05,132.67,132.62,132.56$, $132.53,126.19,125.91,125.82,125.77,125.71$, $125.68,125.29,124.52,124.50,123.49,119.49$, 119.36; 33.83，30.25，30.22，30.20，30.17， $30.14\left(\mathrm{C}_{\text {tert }}, \mathrm{CH}_{3}\right)$. MS (El, $\left.70 \mathrm{ev}\right) \mathrm{m} / \mathrm{z}(\%): 356.1$ $\left(\mathrm{M}^{+}, 58\right), 341.1(100)$. 
Synthesis of (3,4,4-trichlorobut-3-en-1ynyl)(4-nitrophenyl)sulfane (3d) and (1,3,4,4-tetrachlorobuta-1,3-dienyl)(4nitrophenyl)sulfane (4d)

Compounds 3d and 4d were synthesized according to general procedure:

3d: Known compound (25). Spectral data were in agreement with literature values. Yield $(18 \%), \mathrm{R}_{\mathrm{f}}$ $\left(\mathrm{CHCl}_{3}\right): 0.4$; APT NMR, $\delta \mathrm{C}, \mathrm{ppm}$ : 91.65, 83.95 (C $\equiv C), 145.85,139.44,128.46,111.31,125.32$, 125.30, 123.55, 123.56; MS (El, 70 eV) $\mathrm{m} / z(\%)$ : $309.1\left(\mathrm{M}^{+}, 53\right), 226.1(100), 227.1$ (21), 191.1 (29), 156.1 (32), 115.0 (43). Anal.Calcd. for $\mathrm{C}_{10} \mathrm{H}_{4} \mathrm{Cl}_{3} \mathrm{NO}_{2} \mathrm{~S}$ (308.57) C, 38.92; $\mathrm{H}, 1.31 ; \mathrm{S}$, 10.39. Found: C, 38.90; H, 1.29; S, 10.37 .

4d: Yellow, $\mathrm{R}_{\mathrm{f}}$ (n-hexane): 0.2, Yield (35\%); IR spectrum, $\mathrm{V}, \mathrm{cm}^{-1}$ : 3055, 1599, 1579, 1345, 1265,$739 ;{ }^{1} \mathrm{H}$ NMR, $\delta, \mathrm{ppm}: 6.78$ (s, $1 \mathrm{H}$, $>\mathrm{C}=\mathrm{CH}), 8.14(\mathrm{~d}, 2 \mathrm{H}, \mathrm{Ar}-\mathrm{H}, \mathrm{J}=6.6), 7.46(\mathrm{~d}, 2 \mathrm{H}$, Ar-H, $J=6.8) ;{ }^{13} \mathrm{C}$ NMR spectrum, $\delta \mathrm{C}, \mathrm{ppm}$ : 146.30, 139.31, 132.94, 129.82, 129.75, 129.43, 123.41, 123.24; MS (El, $70 \mathrm{eV}) \mathrm{m} / \mathrm{z}(\%): 345.1$ $\left(\mathrm{M}^{+}, 47\right), 343.1$ (35), 347.1 (24), 273.1 (100), 192.1 (57), 308.1 (53), 227.1 (21); Anal.Calcd. for $\mathrm{C}_{10} \mathrm{H}_{5} \mathrm{Cl}_{4} \mathrm{NO}_{2} \mathrm{~S}$ (345.03): C, 34.81; $\mathrm{H}, 1.46 ; \mathrm{S}$, 9.29. Found: C, 34.78; H, 1.43; S, 9.27.

Synthesis of 2-((Z)-1,3,4,4-tetrachlorobuta1,3-dienylthio)phenol (4e) and (E)-2(2,3,3-

trichloroallylidene)benzo[d][1,3]oxathiole

(6) (isomeric mixtures)

Synthesis of $\mathbf{4 e}$ and 6 were carried out by the reaction of $\mathbf{1}(6.6 \mathrm{mmol})$ with 2-mercaptophenol 2e $(26.5 \mathrm{mmol})$ in DMF $(20 \mathrm{~mL})$ with $\mathrm{Et}_{3} \mathrm{~N}(2.5$ $\mathrm{mL})$ at room temperature. After the progress/completion of the reaction was monitored by TLC, the resulting mixture was extracted with chloroform and water. The organic phase was dried by adding anhydrous $\mathrm{Na}_{2} \mathrm{SO}_{4}$ and evaporated under reduced pressure. The crude product was purified by column chromatography with $\mathrm{n}$-hexane over silica gel to give products 4 e and 6 butadiene mixtures with their isomers.

4e and 6 with their isomer mixture: Dark yellow oil, Yield (30\%), $\mathrm{R}_{\mathrm{f}}\left(3 \mathrm{CH}_{2} \mathrm{Cl}_{2} / 1 \mathrm{n}\right.$-hexane): 0.6 ; IR spectrum, $\mathrm{v}, \mathrm{cm}^{-1}$ : $3456(-\mathrm{OH}), 1471$, $1575\left(\mathrm{C}=\mathrm{C}_{\text {arom }}\right) \mathrm{cm}^{-1} ;{ }^{1} \mathrm{H}$ NMR, $\delta, \mathrm{ppm}: 7.40$ (d, $3 \mathrm{H}, \mathrm{Ar}-\mathrm{H}, \mathrm{J}=6.35 \mathrm{~Hz}), 7.35(\mathrm{~d}, \mathrm{H}, \mathrm{Ar}-\mathrm{H}, \mathrm{J}=7.32$ $\mathrm{Hz}), 7.26(\mathrm{t}, 4 \mathrm{H}, \mathrm{Ar}-\mathrm{H}, J=6.8 \mathrm{~Hz}), 6.95(\mathrm{~d}, 4 \mathrm{H}$, Ar-H, J=7.32Hz), $6.85(\mathrm{t}, 4 \mathrm{H}, \mathrm{Ar}-\mathrm{H}, J=7.08 \mathrm{~Hz})$, $6.51(\mathrm{~s}, 2 \mathrm{H},>\mathrm{C}=\mathrm{CH}), 6.24(\mathrm{~s}, \mathrm{H},>\mathrm{C}=\mathrm{CH}), 6.17$ ( $\mathrm{s}, \mathrm{H},>\mathrm{C}=\mathrm{CH}), 5.90-6.12$ ( $\mathrm{s}$, broad, $2 \mathrm{H},-\mathrm{OH})$; ${ }^{13} \mathrm{C}$ NMR spectrum, $\delta \mathrm{C}$, ppm: 156.59, 135.64, $135.51,135.45,135.33,132.66,132.42,132.29$, $131.93,128.63,125.39,123.52,123.19,122.24$, $121.76,121.72,121.67,116.81,116.37,116.24$, 116.16; $\mathrm{MS}(\mathrm{El}, 70 \mathrm{ev}) \mathrm{m} / \mathrm{z}(\%): 280.1$ (6) and 316.1 (4e): $\left(\mathrm{C}_{10} \mathrm{H}_{5} \mathrm{Cl}_{3} \mathrm{OS} ; 279.57\right.$ for compd. 6), $\left(\mathrm{C}_{10} \mathrm{H}_{6} \mathrm{Cl}_{4} \mathrm{OS} ; 316.03\right.$ for compound $\left.4 \mathbf{e}\right)$.

\section{RESULTS AND DISCUSSION}

Reaction of $\mathbf{1}$ with some thiols $\mathbf{2 a - e}$ in ethanol (with $\mathrm{NaOH}$ ) or DMF (with triethylamine) at room temperature gave the thioethers (3a-d, $\mathbf{4 b}-\mathbf{b}$, 5a, 6) (Scheme 1). Also, compounds 4c, 4e and 6 were obtained as isomeric mixtures, their structures were especially identified with GC-MS (+EI) analyses (different retention times of isomers).<smiles>[R]C#C/C(Cl)=C(/Cl)C#C[R]</smiles><smiles>[Z6]SC#[R]C(C)(C)C</smiles>

Scheme 1. Synthetic route to thioethers. 
The reaction of $\mathbf{1}$ with equivalent 2-methyl-2propanethiol $\mathbf{2 a}$ in $\mathrm{EtOH} / \mathrm{NaOH}$ at room temperature provided the mono(thio)substituted-1-buten-3-yne 3a $(27,28)$ and tris-(thio)substituted-1-buten-3-yne 5a. In the IR spectra of $\mathbf{5 a}$, the characteristic absorption of acetylenic bond $\left(\mathrm{C} \equiv \mathrm{C}, 2134 \mathrm{~cm}^{-1}\right)$ appeared in the expected range. Also, the ${ }^{13} \mathrm{C}$ NMR signals for this compound 5a $\delta 93.72,89.92$ corresponded to the acetylenic group $(\mathrm{C} \equiv \mathrm{C})$.

Mono(thio)substituted-1-buten-3-yne compound $\mathbf{3 b}$ obtained from the reaction of $\mathbf{1}$ and benzyl mercaptan $\mathbf{2 b}$, besides mono(thio)substituted product $\mathbf{4 b}$ was obtained in this reaction. Compound $\mathbf{3 b}$ revealed characteristic signals at $\delta(\mathrm{ppm}) 87.88,92.47$ due to acetylenic carbons (in ${ }^{13} \mathrm{C} \mathrm{NMR}$ ), and signals at $\delta 4.05 \mathrm{ppm}$ due to benzyl protons and $\delta$ 7.3-7.4 ppm aromatic protons, together, in the ${ }^{1} \mathrm{H}$ NMR spectra. The other compound 4b exhibited the formation of butadiene skeleton: as evidence, the presence of singlet butadiene proton signal ( $>\mathrm{C}=\mathrm{CH}, \delta 6.48 \mathrm{ppm}$ ) in the ${ }^{1} \mathrm{H}$ NMR spectrum and by the disapperance of acetylenic carbons $(C \equiv C)$ at about $\delta 80-90 \mathrm{ppm}$ in the ${ }^{13} \mathrm{C}$ NMR spectrum. Also, compounds $\mathbf{3 b}$ and $\mathbf{4 b}$ showed $a$ molecular ion peak $(\mathrm{M})^{+}, 278.0$ (3b) and 314.1 (4b), which were agreement with the molecular formulas.

Reaction of the $\mathbf{1}$ with 4-tert-butylbenzenethiol 2c afforded compound 3c $(26,29)$ and two isomers mixture of compound 4c. Isomer's presence was detected by gas chromatography via their different retention times and same molecular mass $(\mathrm{m} / \mathrm{z}=356.1)$. In addition, proton-NMR spectrum of 4c the apperance of two vinyl protons at $\delta=6.14$ and 6.48 ppm supported to formation of two isomers.

When $\mathbf{1}$ was reacted with $\mathbf{2 d}$, compounds $\mathbf{3 d}$ (ref 25) and 4d were obtained. The ${ }^{1} \mathrm{H}$ NMR spectra of $4 \mathbf{d}$ exhibit its characteristic signals at $\delta 8.14,7.46 \mathrm{ppm}$ due to aromatic protons and $\delta 6.78 \mathrm{ppm}$ due to butadiene proton
( $>\mathrm{C}=\mathrm{CH})$. Also, compounds $3 \mathbf{d}\left(\mathrm{M}^{+}, 309.1\right)$ and $4 \mathbf{d}\left(\mathrm{M}^{+}, 345.1\right)$ showed molecular ion peaks, as expected.

The reaction of $\mathbf{1}$ with 2-hydroxythiophenol $\mathbf{2 e}$ in DMF with triethylamine gave a mixture of two butadiene compounds ( $\mathbf{4 e}$ and $\mathbf{6}$ ), each of them having two isomers. This mixture could not be separated with column chromatography. However, especially, these butadienes and their isomers were separated and characterized by GCMS method. Furthermore, while 4 e had $\mathrm{OH}$ protected structure, compound $\mathbf{6}$ was obtained by the ring formation. The GC-MS chromatogram for $\mathbf{4 e}$ and $\mathbf{6}$ is shown in Figure 1. It can be seen that the compound $\mathbf{6}$ with two isomers is evident at $8.21 \mathrm{~min}$, together with the peak at $8.37 \mathrm{~min}$. Each isomers of $\mathbf{6}$ has the same molecular ion peak of m/z 280.1. (Fig. 2 (a) and (b)) and same mass fragmentation pattern. Also, literature survey showed that similar ring formation between 2-nitro-1,1,3,4,4-pentachloro-1,3butadiene and 2-hydroxythiophenol $\mathbf{2 e}$ in room temperature, with $45 \%$ yield (15).

The compound $\mathbf{4 e}$ also contains two isomers with the retention time of (RT) $8.63 \mathrm{~min}$ and $8.78 \mathrm{~min}$. Each isomers of $\mathbf{4 e}$ has the same molecular ion peak of $\mathrm{m} / \mathrm{z} 316.1$ (Figure 2 (c) and (d)) and same mass fragmentation pattern. Compound $\mathbf{4 e}$ had mono(4-hydroxyphenylthio)substituted-1,3butadiene structure. Moreover, there was a reaction in the literature that tetrakis(4hydroxyphenylthio)-substituted-1,3-butadiene was synthesized from 1,1,3,3,4,4hexachlorobutene and 2-hydroxythiophenol $\mathbf{2 e}$ in the presence of triethylamine (30).

Furthermore, in the ${ }^{1} \mathrm{H}$ NMR spectrum of butadiene mixtures and their isomers (4e and $\mathbf{6}$ ), the typical absorptions were observed such as $\mathrm{OH}$ signals at $\delta$ 5.90-6.12 ppm (broad), butadiene's proton signals $(>\mathrm{C}=\mathrm{CH})$, at $\delta 6.51,6.24,6.17$ ppm) and aromatic ring signals at $\delta 6.8-7.46$ ppm region, which provide additional supporting evidence for their characterization.

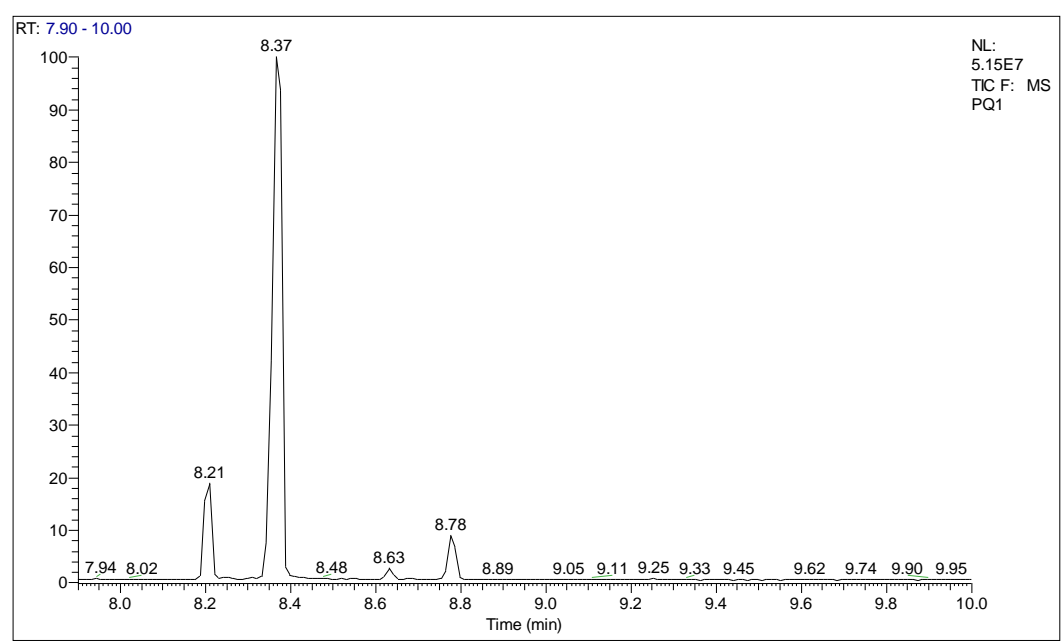

Figure 1. GC-MS (+EI) chromatogram of butadiene structures (4e and 6) with their isomers. 


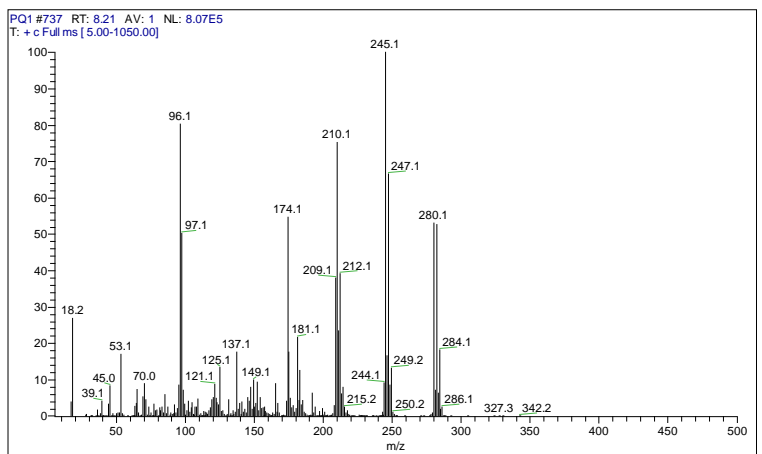

(a)

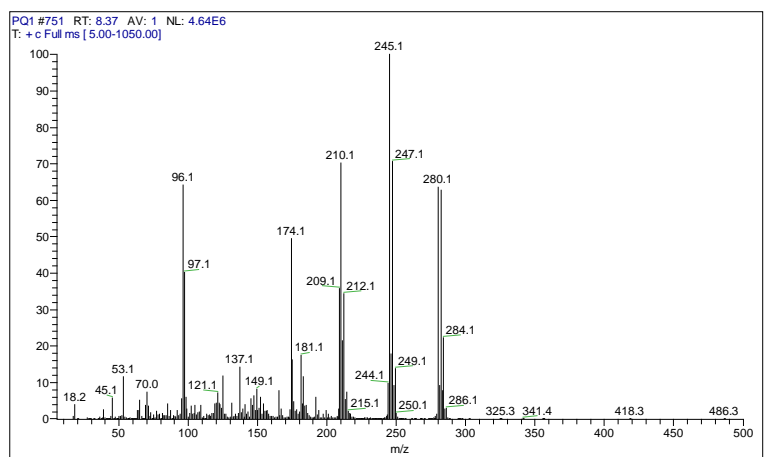

(b)

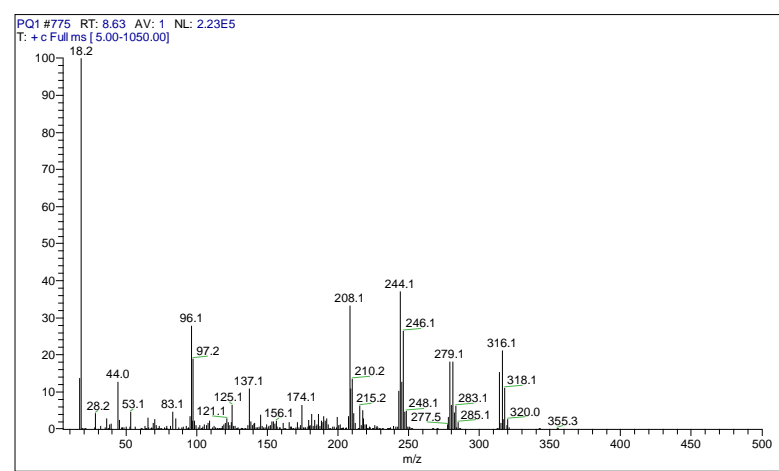

(c)

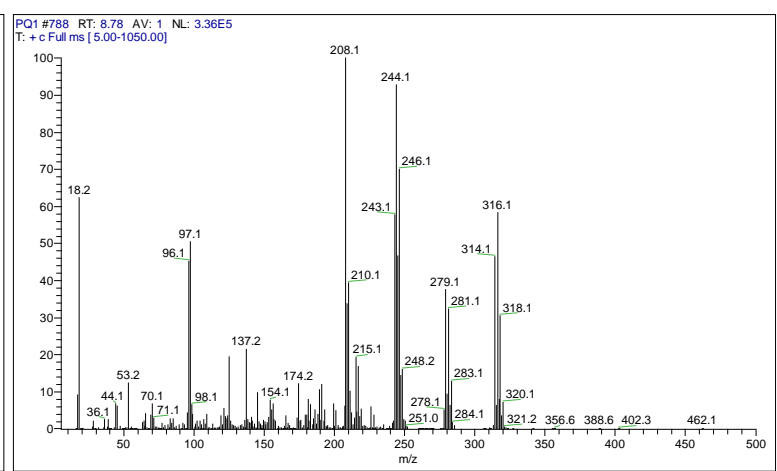

(d)

Figure 2. GC-MS (+EI) spectra for two isomers of 6 at RT: 8.21 (a) and 8.37 (b) $\mathrm{min}, \mathrm{m} / \mathrm{z}:\left(\mathrm{C}_{10} \mathrm{H}_{5} \mathrm{Cl}_{3} \mathrm{OS}\right.$; 279.57). Additionally, GC-MS (+EI) spectra for two isomers of $4 \mathrm{e}$ at RT: 8.63 (c) and 8.78 (d) $\mathrm{min}, \mathrm{m} / \mathrm{z}$ : $\left(\mathrm{C}_{10} \mathrm{H}_{6} \mathrm{Cl}_{4} \mathrm{OS} ; 316.03\right)$

\section{CONCLUSION}

Thioether moieties revealed pronounced biological value such as fungicidal properties. In this study, thio-substituted 1,3-butadienes and butenynes were obtained from the reactions between thiols and compound $\mathbf{1}$ in EtOH or DMF at room temperature. Also, some isomers were identified on the basis of GC-MS(+EI) analysis with different retention times (RT). The structures of S- substituted compounds were elucidated by elemental analyses, (GC-MS(+EI)), IR, ${ }^{1} \mathrm{H},{ }^{13} \mathrm{C}$ or APT NMR spectroscopies.

\section{ACKNOWLEDGMENTS}

This study was funded by Istanbul University with the project number (NP-42986). I thank the Research Fund of Istanbul University Cerrahpasa for financial help.

\section{REFERENCES}

1. Kang X, Yan R, Yu G, Pang X, Liu X, Li X, Xiang $L$, Huang $G$. Iodine-Mediated Thiolation of Substituted Naphthols/Naphthylamines and Arylsulfonyl Hydrazides via C(sp2)-H Bond Functionalization. J. Org. Chem. 2014; 79: 10605-10.
2. Clayden J, MacLellan P. Asymmetric synthesis of tertiary thiols and thioethers. Beilstein J. Org. Chem. 2011; 7: 582-95.

3. Auger S, Merand Y, Pelletier JD, Poirier D, Labrie F. Synthesis and biological activities of thioether derivatives related to the antiestrogens tamoxifen and ICI 164384. J. Steroid. Biochem. Mol. Biol. 1995; 52(6): 547-65.

4. Schopfer U, Schlapbach A. A general palladium-catalysed synthesis of aromatic and heteroaromatic thioethers. Tetrahedron. 2001; 57: 3069-73.

5. Leroux F, Jeschke $P$, Schlosser $M$. aFluorinated Ethers, Thioethers, and Amines: Anomerically Biased Species. Chem. Rev. 2005; 105(3): 827-56.

6. H. Bluestone, Polyunsaturated sulfides and sulfones and method of preparing same. US Patent 3,021,370, Feb. 13. 1962.

7. Schmidt A, Rahimi A, Gjikaj M. SulfanylSubstituted [3]Cumulenes and Buta-1,3-dienes from a Tetrakis(pyridinium)-Substituted Butadiene. Synthesis. 2009; 14: 2371-8.

8. Zapol'skii VA, Nutz E, Namyslo JC, Adam AEV, Kaufmann DE. Chemistry of Polyhalogenated 
Nitrobutadienes, 2: Synthesis of $\mathrm{N}$ -

Tetrachloro $\neg$ allylidene- $\mathrm{N}^{\prime}$-arylhydrazines by a Formal Synproportionation Reaction, Synthesis. 2006; 17: 2927-33.

9. Yoshimatsu M, Kinoshita S, Sugimoto T. Palladium-Catalyzed Terminal Alkyne Coupling Reaction of $\beta$-Bromo- $\beta$-phenylthio or $\beta$ Methylthio-a-trifluoromethyl Enol Ethers: a Convenient Synthesis of 2-Sulfonyl-1-buten-3ynes. Chem. Pharm. Bull. 1999; 47(10): 1497500 .

10. Backvall JE, Chinchilla R, Najera C, Yus M. The Use of Sulfonyl 1,3-Dienes in Organic Synthesis. Chem. Rev. 1998; 98: 2291-312.

11. Padwa A, Bullock WH, Norman BH, Perumattam J. (Nitroaryl)sulfinyl-substituted allenes. Novel and convenient propargyl alcohol synthons in $4+2$ cycloaddition chemistry. $\mathrm{J}$. Org. Chem. 1991; 56: 4252-9.

12. Ibis C, Şahinler Ayla S. Mono-, bis-, tris-, and tetrakis(thio)substituted butenynes from halogenated butenes and butadienes. Phosphorus Sulfur Silicon Relat Elem. 2017; 192(6): 597-601.

13. Ibis C, Beyazit N. The synthesis of new thiosubstituted butadienes, butenynes and butatrienes Arkivoc. 2010; ix: 244-56.

14. Ibis C, Sahinler Ayla S, Beyazit N, Bahar H, Synthesis of Novel Thioethers and Sulfoxide Compounds, Phosphorus. Sulfur. Silicon. Relat. Elem. 2013; 188: 1643-51.

15. Ibis C, Ozkok F. The Synthesis of Novel S-, S,S-, S,S,S-, S,O-, N,S-Substituted Halogenobuta-1,3-dienes. Acta Chim. Slov. 2012; 59:294-301.

16. Ibis C, Yilmaz N. Neue N,S-substituierte Dienverbindungen aus reaktionen von mono(arylthio)substituierten polyhalo-2nitrodienen mit aminen. Phosphorus Sulfur Silicon Relat Elem. 2000; 159: 87-98.

17. Ibis C, Göksel FS, Aydınlı G. New N,SSubstituted Dienes from the Reactions of Some Aliphatic Mono(thio)substituted Nitrodienes with Aromatic Primary Amines and Cyclic Amines. Phosphorus Sulfur Silicon Relat Elem. 2003; 178: $777-83$.

18. Ibis C, Yildirim H. The Synthesis of Novel S-, S,S-, S,S,S-, and N,S-Substituted Nitrodienes from Polyhalonitrodienes and Thiols. Phosphorus Sulfur Silicon Relat Elem. 2011; 186: 2236-49.
19. Ibis C, Sahin A, The Synthesis and Characterization of Some Novel Thioethers: Thio-Subsituted [3]Cumulenes, -1-Buten-3-ynes and Buta-1,3-dienes. Bull. Korean Chem. Soc. $2010 ; 31,2255-60$.

20. Ibis C, Sahin A, Synthesis of new sulfanyl-, sulfinyl-, and sulfonyl-substituted polychlorobuta-1,3-dienes. Russ. J. Org. Chem. 2016; 52(6): 897-902.

21. Roedig A, Zaby G. Untersuchungen zum Mechanismus der Bildung von Tetrakis(organylthio)buteninen und -butatrienen aus Perchlorbutenin bzw. -butatrien mit Thiolaten. Liebigs Ann. Chem. 1979; 1979(10): 1626-34.

22. Roedig A, Zaby G. Pentakis(organylthio)1,3-butadiene aus Perchlorbutenin und Tetrakis(organylthio)butatrienen oder buteninen mit Thiolen und Thiolaten. Liebigs Ann. Chem. 1979; 1979(10): 1614-25.

23. Roedig A, Zaby G. Reaktionen von Poly(organylthio)buteninen und -butatrienen mit Elektrophilen. Chem. Ber. 1980; 113: 3342-51.

24. Roedig A, Ibis C, Zaby G. Reaktionen von Polychlor-1,3-butadienen und Polychlorbutenen mit Thiolaten. Chem. Ber. 1981; 114: 684-98.

25. Ibis C. Neue Thioether und Disulfidverbindungen aus mono(arylthio)substitutiertem 2-nitrotetrachlor1,3-butadien und neue thioether mit butadien-, butin und butenin struktur aus hexachlorbuten. Phosphorus Sulfur Silicon Relat Elem. 1996; 118: 49-60.

26. Roedig A, Zaby G, Scharf W.

Tetrakisthiobutatriene aus Perchlorbutenin und Thiolate. Chem. Ber. 1977; 110: 1484-91.

27. Roedig A, Zaby G.

Tetrakis(organylthio)butenine aus

Perchlorbutenin und

Tetrakis(organylthio)butatrienen mit Thiolaten. Liebigs Ann. Chem. 1979; 1979(10): 1606-13.

28. Ibiş C, Gurun C. Neue Sulfide mit Btin-, Butenin- Und Butadien Struktur. Sulfur Letters. 1992; 14: 251-7.

29. Ibis C. Review of Faculty of Science, University of Istanbul, Serie C, 1989; 53: 19.

30. Ibis C, Sahinler Ayla S, The synthesis and spectral investigation of new thiosubstituted butadienes and butenynes. Arkivoc. 2008; xvi: 29-37. 